\title{
Analysis of Caving Behaviour Using a Synthetic Rock Mass - Ubiquitous Joint Rock Mass Modelling Technique
}

\author{
B. Sainsbury Itasca Australia Pty Ltd, Australia \\ M.E. Pierce Itasca Consulting Group, Inc., USA \\ D. Mas Ivars Itasca Geomekanik AB, Sweden
}

\begin{abstract}
Traditional approaches to cave analysis do not provide a means for the robust examination of how key inputs such as fracture orientation and fracture persistence impact rock mass strength and its response to caving. A ubiquitous jointed rock mass (UJRM) technique has been developed to represent rock mass strength anisotropy and scale effects within FLAC3D, as determined from synthetic rock mass (SRM) testing. The development of a UJRM within large-scale numerical simulations of caving show that variations in joint orientation have a significant effect on the evolving cave shape and the rate of cave propagation. The UJRM technique has been applied to a back analysis of caving and the associated pit slope failure mechanism at the Palabora mine in South Africa.
\end{abstract}

\section{Introduction}

The cave propagation behaviour of a jointed rock mass is strongly governed by the unique nature of joints and discontinuities, together with the intact strength of rock-bridges that make up a rock mass. As part of the industry sponsored Mass Mining Technology (MMT) project, a SRM modelling technique has been developed (Pierce et al., 2007; Mas Ivars et al., 2008) to allow for the detailed consideration of the rock mass joint fabric. The SRM methodology uses the particle flow code (PFC3D) (Itasca, 2007a) to explicitly represent a discrete fracture network (DFN) embedded within an intact rock matrix. Through simulated testing of these synthetic materials, properties such as strength anisotropy and brittleness can be obtained. There is currently no way to derive these properties from empirical techniques.

At present, it is not practical to simulate large-scale geological processes within $P F C 3 D$ due to the computational intensity of the numerical technique. For this reason, continuum codes are required to ensure reasonable computation times. This paper discusses the practical application of implementing a strainsoftening, ubiquitous joint (subiquitous) constitutive model - referred to as a UJRM in large cave-scale FLAC3D (Itasca, 2006) models. A case study application of the SRM-UJRM technique is also presented.

\section{Background}

Traditionally, cave assessment has only considered whether a rock mass would cave or stall at a specified mining hydraulic radius. This determination has been based on empirical design charts that relate cavability to the Mining Rock Mass Rating (MRMR) and hydraulic radius (m) of the mining footprint (Laubscher, 2000).

The results of a scoping study at the commencement of the MMT project concluded that a numerical approach to cavability assessment is the most powerful and flexible tool for future cave analyses. Numerical modelling techniques that assume isotropic rock mass strength have been applied to predict cave behaviour for many years. However, in order to fully understand the evolving cave shape and propagation rates, which have a significant affect on the location and operation of key mine infrastructure, the in situ joint fabric must be considered. This has lead to the development of SRM technology. 


\subsection{Synthetic rock mass testing}

SRM testing has been developed (Pierce et al., 2007; Mas Ivars et al., 2008) to allow for the detailed consideration of the rock mass joint fabric in the determination of rock mass strength anisotropy and scale effects. The SRM methodology uses PFC3D to explicitly represent a DFN, honouring in situ joint measurements (i.e. spacing, trace length and orientation), that is embedded within a bonded assembly, as illustrated in Figure 1. The size of a SRM sample is generally greater than $10 \times 10 \times 10 \mathrm{~m}$ but is determined by the persistance of the fracture network.

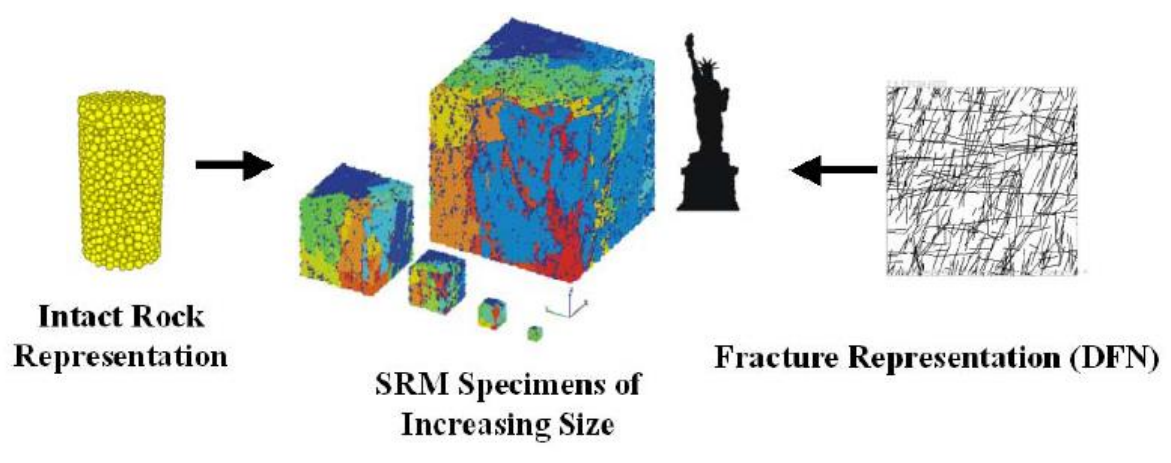

\section{Figure 1 Generation of SRM samples from intact and superposition of fracture network}

The material response of SRM samples has been validated through:

- A comparison of fracture orientations produced when a SRM sample is subjected to the same mining induced stress path to in situ rock mass that has seismic monitoring data available (Figure 2(a)).

- A comparison of SRM fragmentation predictions with drawpoint observations (Figure 2(b)).

B. (Right) Comparison of fragmentation in SRM tests with fragmentation measured in drawpoints

A. (Below) Comparison of fracture orientations predicted by SRM testing and those inferred from microseismic data
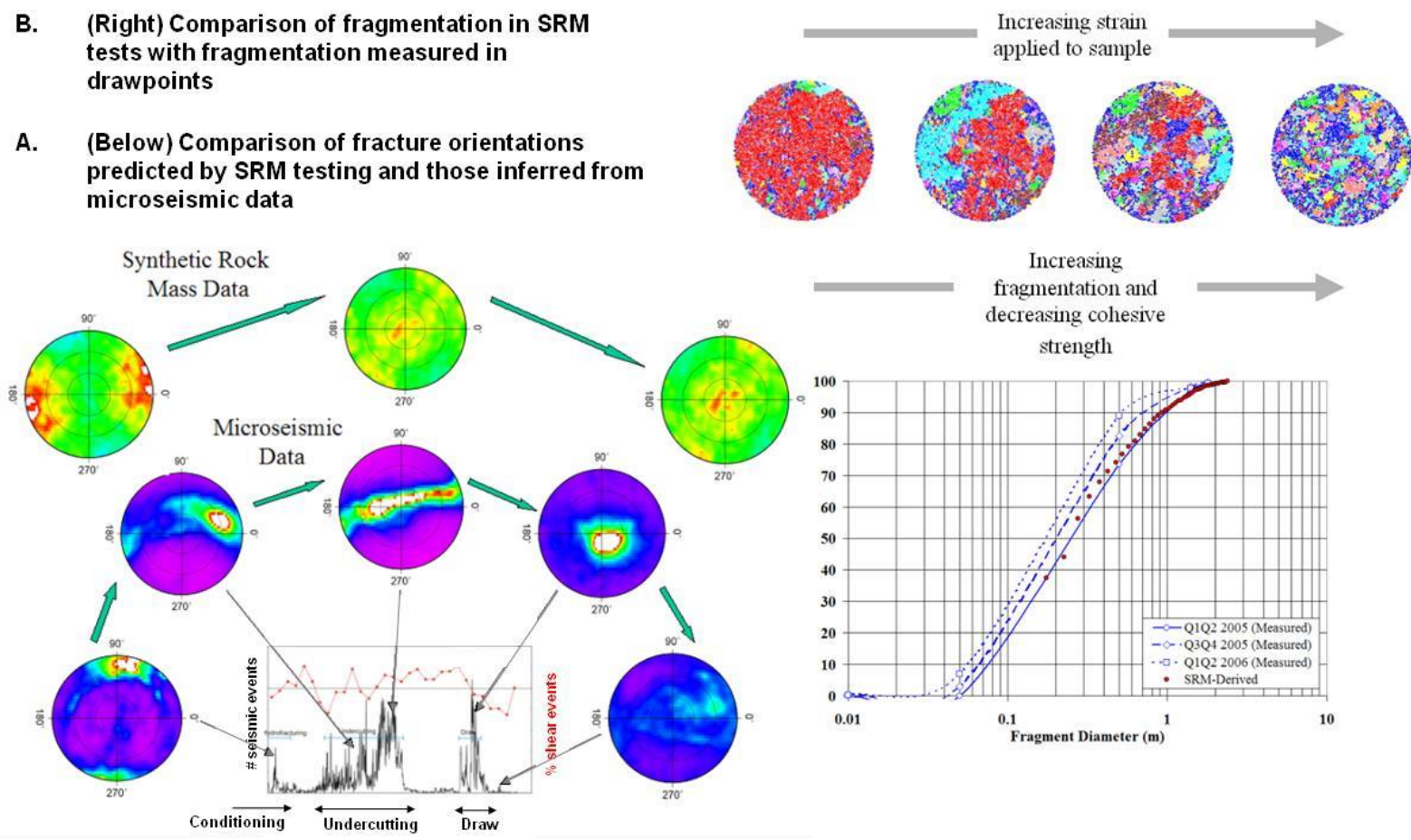

Figure 2 Validation of SRM response based on fracture modes and fragmentation 
In addition, the SRM technique for representing jointed rock masses has been validated based on a rigorous back-analysis of cave behaviour. The shape and advance rate of the cave (defined by displacement and rock mass degradation) were tracked as a function of production within a numerical simulation of the Northparkes E26 Lift 2 mine. The results were compared to in situ measurements of seismic activity, open-hole observations and TDR data. Figure 3(a) and (b) provide a summary of the results from this analysis. The rapid advance of the yield zone up through the orebody to the base of Lift 1 is reproduced along with hangups within the more competent, less brittle volcanic lithology. A discussion regarding the nomenclature used in these figures is provided in Section 3 of this paper.

The results presented in Figure 3 were not produced from an iterative numerical modelling process in which rock mass properties were adjusted to achieve a match with in situ observations. Rather, the properties obtained from the SRM tests (along with reasonable assumptions regarding the dilation angle and tensile strength) were used directly in the cave-scale production simulation.

A. Numerical simulation of cave shape at Northparkes Lift 2

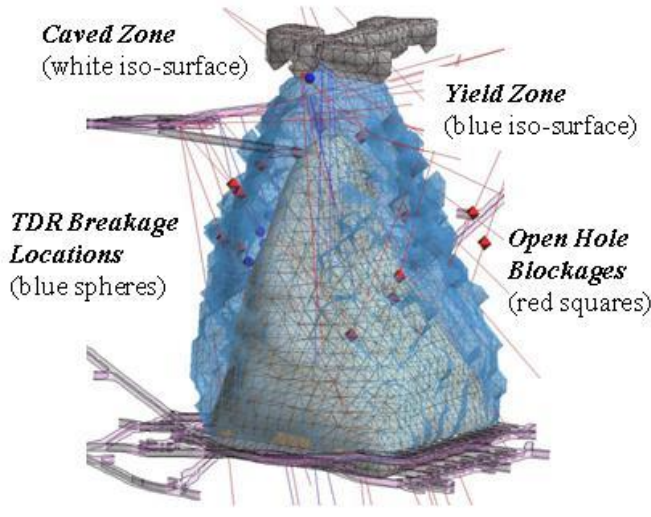

\section{B. Numerical simulation of cave advance at} Northparkes Lift 2

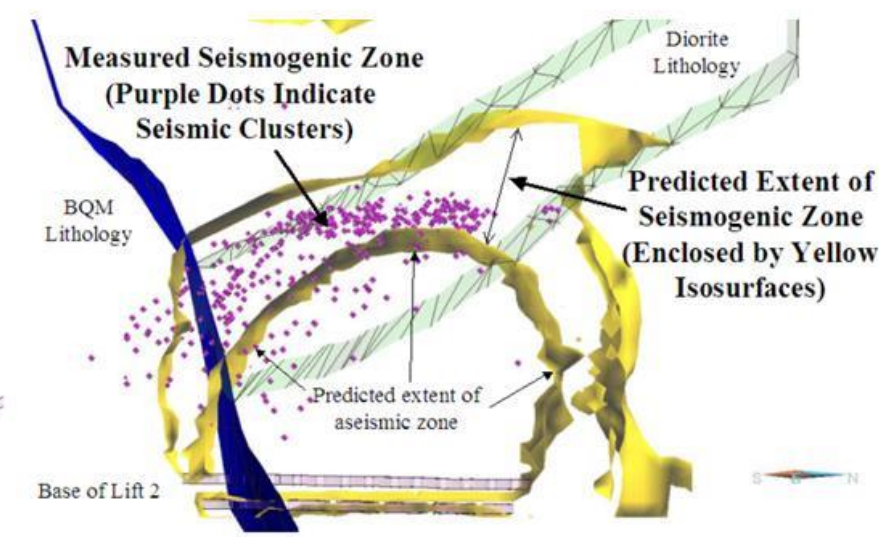

Figure 3 Numerical cave analysis: Northparkes E26 Lift 2 mine

\section{$3 \quad$ Numerical model of caving}

\subsection{Definition of cave regions}

A conceptual model of caving has been developed by Duplancic and Brady (1999). The model includes four main behavioural regions that have also been defined within the numerical model of caving. A schematic diagram representing the relationship between the regions is presented in Figure 4. The characteristics of each region are described below:

- Pseudo-continuous domain - The rock mass in this region behaves mainly elastically. Rock mass behaviour and properties are those of an undisturbed rock mass.

- Seismogenic zone - Microseismic activity occurs in this region primarily due to discontinuity damage and the initiation of new fractures. The overall advance rate, thickness and spatial distribution of the seismogenic zone within the numerical model of caving has been determined by the criterion in Equation (1) (after Diederichs, 1999).

$$
\sigma_{1}=\sigma_{3}+[0.2 \text { to } 0.4] * \mathrm{UCS}_{\text {lab }}
$$

This simple criterion has been successfully applied in a cave-scale model of Northparkes E26 Lift 2 - as illustrated in Figure 3(b) and at the Palabora mine (Figure 12).

- Yielded zone - This region describes rock mass that has lost some or all of its cohesion and provides minimal support to the overlying rock mass. Within the conceptual model of caving, Duplancic and Brady (1999) refer to this zone as the zone of discontinuous deformation. The numerical definition of the yield zone includes zones that have degraded to zero cohesion or tensile strength. This 
criterion was established through a back-analysis of the Northparkes E26 Lift 2 cave - Figure 3(a) and has been validated at the Palabora mine (Figures 9-12).

- Caved Zone - This region consists of rock blocks that are moving towards the draw points in response to production. This region is also referred to as the mobilised zone. The cave zone in the numerical model has been defined by those zones that have experienced a displacement greater than $1 \mathrm{~m}$. This criterion was established though the back-analysis of the Northparkes E26 Lift 2 cave see Figure 3(a) - and has been validated at the Palabora mine (Figures 9-12).

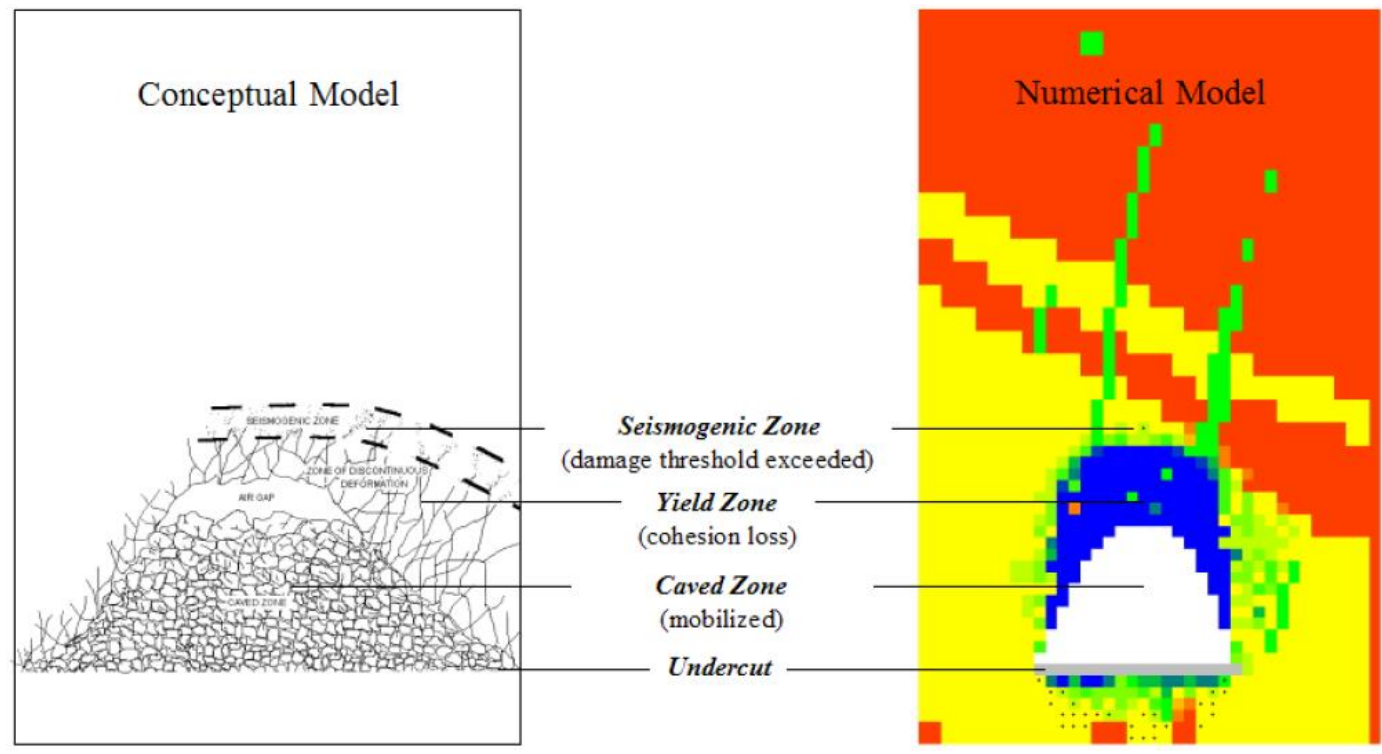

\section{Figure 4 Conceptual versus numerical model of caving}

\subsection{Simulation of production within the numerical model}

To simulate the undercutting and production process within the numerical model, at the start of each advance increment, the undercut zones are simulated with properties consistent with a fully fragmented and bulked caved material. Draw is simulated by applying a small downward-oriented velocity to all grid points in the back of the undercut (Figure 5). This velocity is set low enough to ensure pseudo-static equilibrium throughout the model. The mass of material drawn from a zone over a solve increment is calculated as follows:

$$
m=V t A \rho
$$

Where:

$\mathrm{V}=$ Average velocity of the zone gridpoints in the undercut roof $(\mathrm{m} / \mathrm{s})$.

$\mathrm{t}=$ Elapsed model time.

$\mathrm{A}=$ Zone area in plan.

$\rho=$ Zone density.

By summing the masses drawn by all the gridpoints, the total production from the cave within the model may be calculated. Different draw strategies may be simulated by varying the velocity in gridpoints across the top of the undercut. 
Pre-Mining

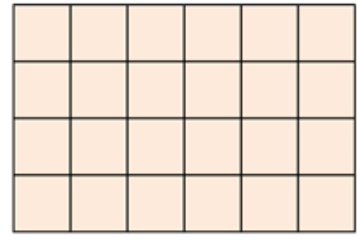

Undercutting

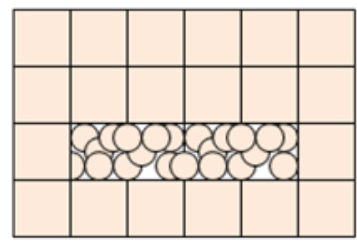

Draw
Simulation

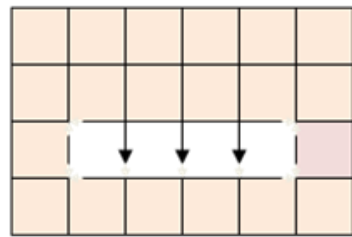

Cave Propagation

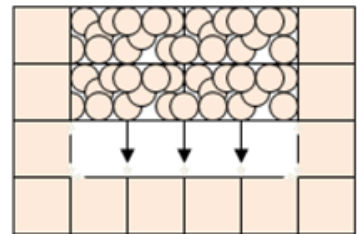

Bulked caved rock is simulated in the undercut zones. The undercut volume is then deleted, and the support it provided to the surrounding rock mass is replaced with equivalent boundary forces on the floor and walls of the undercut. Draw is simulated by applying a downwardoriented velocity to grid points in the back of the undercut. This velocity is set low enough to ensure pseudo-static equilibrium throughout the model (i.e., to avoid dynamic "pulling" of the overlying material). The velocity is selected based on numerical simulations of laboratory tests on the rock mass material. The model is kept in small-strain mode to retain the undercut roof geometry.

The mass of material "drawn" from a zone over a solve increment is calculated as follows:

$$
m=v t A \rho
$$

$V=$ velocity of the gridpoints $(\mathrm{m} / \mathrm{s}) \quad t=$ elapsed model time

$A=$ zone area in plan

$\rho=$ zone density.

Density within a zone is adjusted automatically in response to the volumetric expansion. This expansion can result from dilation during shear failure or tensile failure opening of joints. Based on the relationship below, bulking of the rock mass is an emergent property. The amount of bulking is capped by a user-defined bulking limit (B).

$$
\begin{array}{ll}
\qquad \rho_{d=}=\rho_{s} /(1+B) \\
\rho_{d}=\text { dry density of caved rock } & \rho_{\mathrm{s}}=\text { solid density of in situ rock } \\
B=\text { bulking factor }=\mathrm{n} /(1-\mathrm{n}) & \mathrm{n}=\text { porosity. }
\end{array}
$$

\section{Figure 5 Numerical simulation of production draw}

\subsection{Simulation of bulked cave material within the numerical model}

The density of the rock mass within the evolving cave volume is adjusted automatically to reflect the volumetric changes that accompany bulking according to the following relation (after Lorig and Pierce, 2000):

$$
\rho_{d}=\rho_{s} /(1+B)
$$

Where:

$\rho_{\mathrm{d}}=$ Dry density of caved rock.

$\rho_{\mathrm{s}}=$ Solid density of in situ rock.

$B=$ Bulking factor $=n /(1-n)$.

$\mathrm{n}=$ Porosity.

The bulking factor within the numerical simuation of caving is set a maximum value that cannot be exceeded. This value has been determined by Lorig and Pierce (2000) who report that the modulus of caved rock at a porosity of 0.3 is approximately $250 \mathrm{MPa}$. This porosity is equivalent to a bulking factor of 0.43 or $43 \%$. It is important to note however, that not all zones within the yielded rock mass achieve this maximum value - their densities (and bulk and shear modulii), are calculated automatically, based on the instantaneous volumetric strain.

The modelling methodology described herein allows all three, yield, cave and seismogenic zones to evolve as a result of production. They are identified via periodic assessment of accumulated plastic strain, displacement and principal stress ratios during model stepping. The cave volume is not introduced manually into the model; rather it is allowed to develop based on the specified draw strategy, evolving induced stress conditions and the simulated constitutive behaviour of the rock mass. In doing so, hang-ups, over-breaks and rapid advance rates can all be predicted. 


\section{Representation of jointed rock mass strength for caving analysis}

At present it is not practical to simulate large-scale mining/geological processes within $P F C 3 D$ due to the computational intensity of the numerical technique. For this reason, continuum codes such as $F L A C 3 D$ and $3 D E C$ are required to ensure reasonable computational times. Developments in the engineering methodology used to represent jointed rock masses for cave simulations have lead to the development of the SRM-UJRM approach. This methodology, outlined in Sainsbury et al. (2008) allows the strength anisotropy and scale effects derived from SRM testing to be quantified within FLAC $3 D$.

\subsection{Ubiquitous joint rock mass}

The subiquitous constitutive model in FLAC3D is routinely used to represent laminated materials that exhibit non-linear material hardening or softening. This application of this constitutive model has shown that the assignment of ubiquitous joint orientations at the zone level (from a known joint orientation distribution) results in realistic rock mass behaviour response and yields properties that are consistent with empirical techniques (Sainsbury et al., 2008; Clark, 2006). The assignment of a joint dip, dip direction and radius is achieved via a random sampling procedure from a rock mass DFN. The persistence of joints is honoured throughout the $F L A C 3 D$ grid via extrapolating the joint dip and dip direction to adjoining zones.

The propagation of damage within a UJRM sample can be seen through the progressive degradation of matrix cohesion and ubiquitous joint-failure plots at various stages of UJRM sample loading, illustrated in Figure 6.

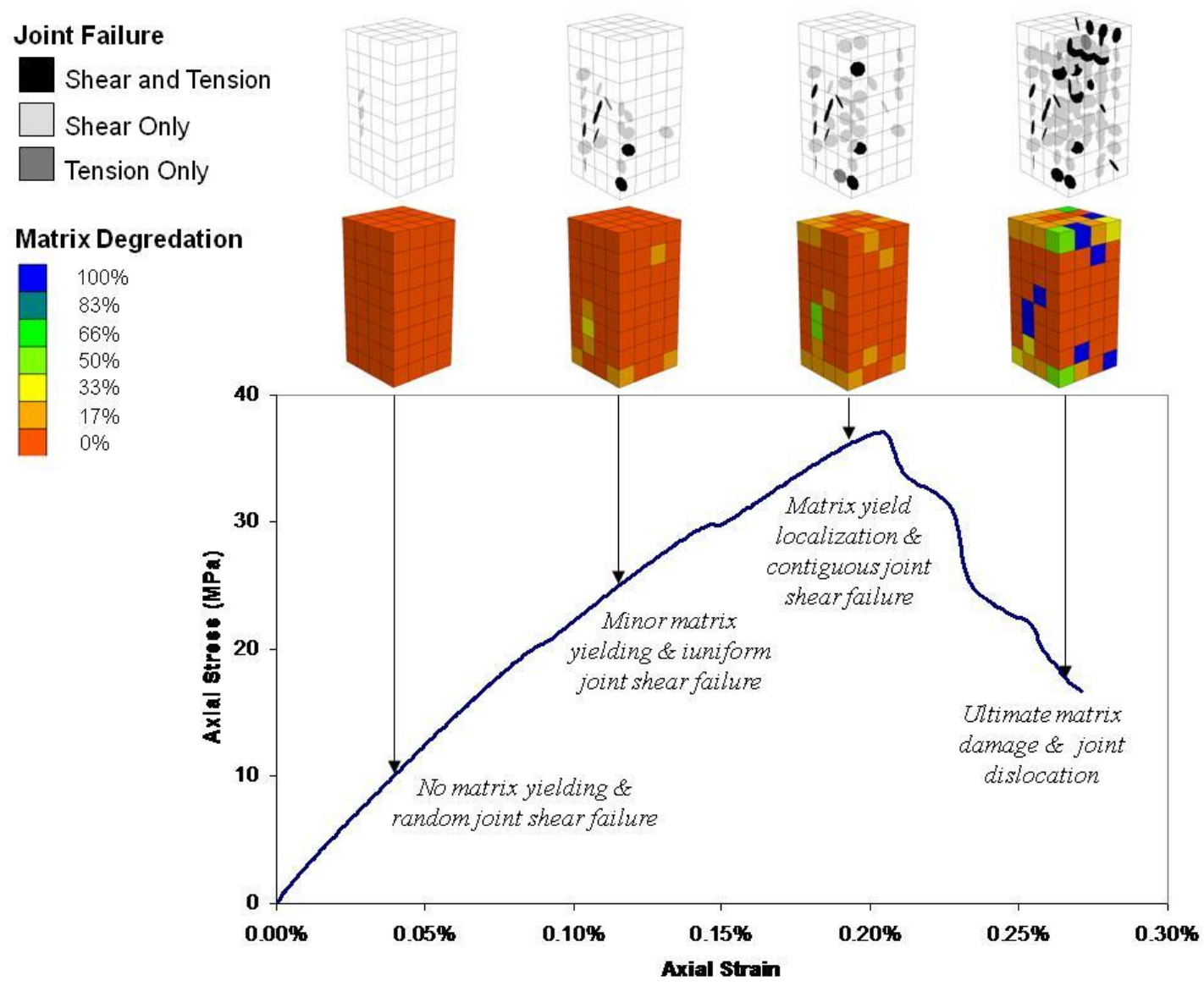

Figure 6 Stages of damage within a UJRM specimen tested under unconfined compression

Calibration of the subiquitous material response in FLAC3D with SRM test results has been termed the SRM-UJRM approach for representation of jointed rock masses. By this methodology, UJRM samples are calibrated to SRM test results under three different stress paths (UCS, triaxial and direct tension), in three 
different loading directions and at three different samples sizes. In each of these environments, not only is the peak and post-peak response matched, but the failure mechanisms, determined from SRM testing, is also honoured. An example of a calibrated rock mass is provided in Figure 7. Currently, the brittleness of a rock mass is best estimated through SRM testing undertaken on spherical samples that are subjected to the expected mining induced stress path (Pierce et al., 2007). The standard suite of SRM tests described in Mas Ivars et al. (2008) is being further developed to ensure that estimates of brittleness determined from this environment is able to accurately represent the conditions during cave propagation.

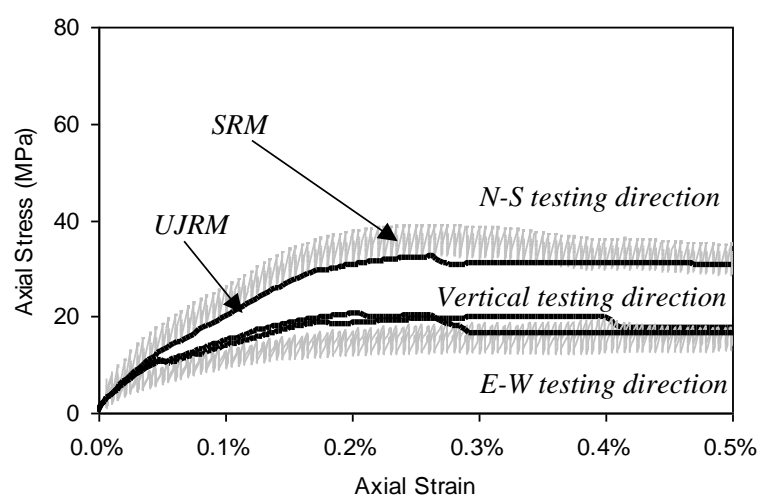

(a) Unconfined Compressive Strength

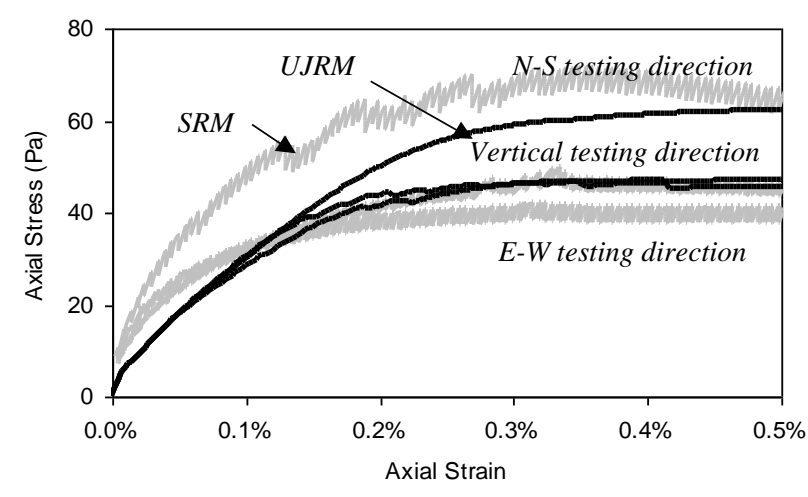

(b) Triaxial at 5 MPa Confinement

Figure 7 Calibrated SRM-UJRM jointed rock mass in UCS and triaxial compression

\section{Caving analysis using a UJRM model}

The UJRM approach for the representation of rock mass strength has been able to represent strength anisotropy apparent in simulated SRM rock masses (Sainsbury et al., 2008). In order to demonstrate the importance of detailed consideration of the in situ joint fabric in caving analyses, four jointed rock masses have been simulated using the UJRM methodology. Each of the rock masses has the same commonly defined rock mass properties $\left(\sigma_{\mathrm{c}}, m_{\mathrm{i}}\right.$, GSI). However, in each of the rock masses, the persistence and orientation of the joint fabric have been modified. The jointed rock mass scenarios include:

- Random joints; i.e. isotropic rock mass.

- Horizontal joints.

- Vertical joints.

- Joints orientated at $45^{\circ}$.

Using the rock masses described above, cave-scale models have been constructed which all have the same principle stress direction (horizontal), mining footprint $(200 \times 200 \mathrm{~m})$ and production schedule. The mobilised zone, after 3.9 Mt of production has been defined in each of the models and is presented in Figure 8. Compared to the empirical approach for cave analysis, where the rock mass is considered to be an isotropic material (Figure 7(a)), the use of a UJRM allows significant variation (Figure 7(b)-(d)) in the cave shape and rate of propagation to emerge as a result of the joint orientation. 
A. Isotropic
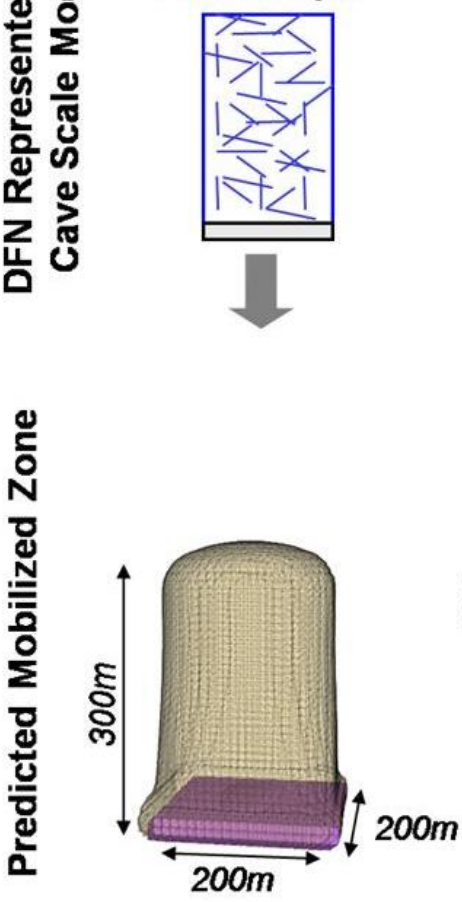

B. Horizontal
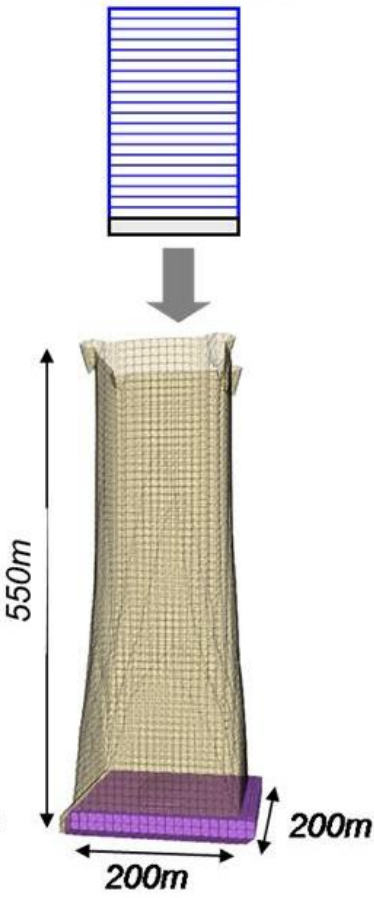

C. Vertical

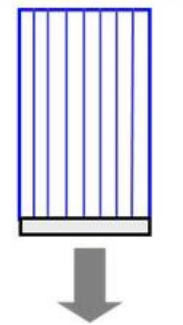

D. Dip $45^{\circ}$

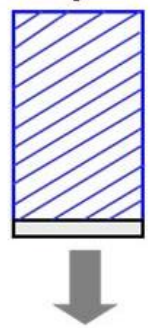

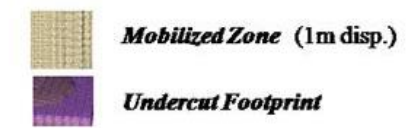

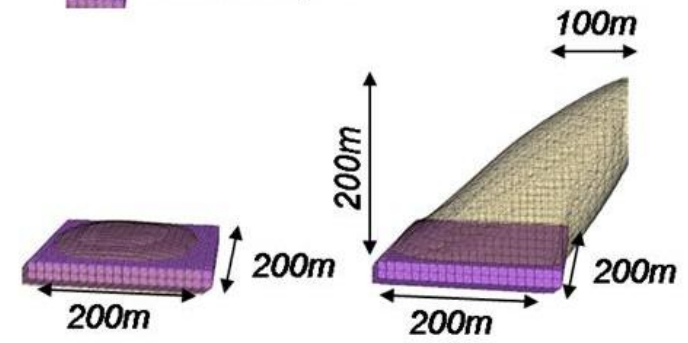

Figure 8 Cave scale model results for varying joint orientations

Based on the simplistic cave models presented, the following conclusions can be made:

- Joints that are orientated perpendicular to the direction of draw (i.e. in most cases horizontal joints) are most favourable for cave propagation. The mobilised zone advances vertically at the most rapid rate. The rate at which the cave zone progresses is rapid and far exceeds the draw rate.

- Joints that are orientated parallel to the direction of draw (i.e. in most cases vertical joints) are not favourable for cave propagation. Minimal displacement of the rock mass is achieved above the mining footprint. In this scenario, shear failure of the rock bridges must occur to enable this rock mass to yield.

- Joints that are orientated at an angle to the direction of draw result in a preferred cave propagation direction. The principle stress direction can either promote shear and tensile failure along the existing joints, causing displacement of the rock mass beyond the lateral extents of the mining footprint, or cause clamping of the joints and result in hang-ups.

\section{Back-analysis of cave behaviour at the Palabora mine}

A back-analysis of the caving behaviour of Rio Tinto's Palabora mine has been conducted to provide verification of the SRM-UJRM technique for jointed rock mass representation. The Palabora mine began operations as an open cut copper mine in 1964. Today it is the world's deepest open cut mine, approximately $450 \mathrm{~m}$ deep and measures nearly two $\mathrm{km}$ in diameter. A change in mining method to block caving was implemented in 2000. Soon after the breakthrough of the block cave to the base of the open pit, a significant pit slope failure occurred on the north wall, as illustrated in Figure 9(a). The open pit failure has jeopardised the integrity of critical infrastructure and leads to potential sterilisation and dilution of the ore reserve. Based upon initial back-analyses of the failure, the failure mechanism has been attributed to a persistent joint set that intersects the cave volume at depth (Brummer et al., 2006).

A series of SRM tests were conducted on the four major geotechnical domains at Palabora (Mas Ivars et al., 2008). A calibrated UJRM was subsequently developed for each of the domains and used within a large 
cave-scale FLAC $3 D$ model that simulated production from the mine. An example of the calibrated tests results for the carbonatite unit at Palabora is illustrated in Figure 7. A complete summary of each of the calibrated results is provided in Sainsbury et al. (2008). During the simulated production schedule, each of the four cave behavioural regions (Section 3) were tracked and compared to observations made at the Palabora mine during that time period.

Figure 9 (b) presents the results of the large-scale pit slope failure mechanism that has been reproduced in the numerical model. The location and timing of this failure mechanism within the numerical model compared to well site observations.

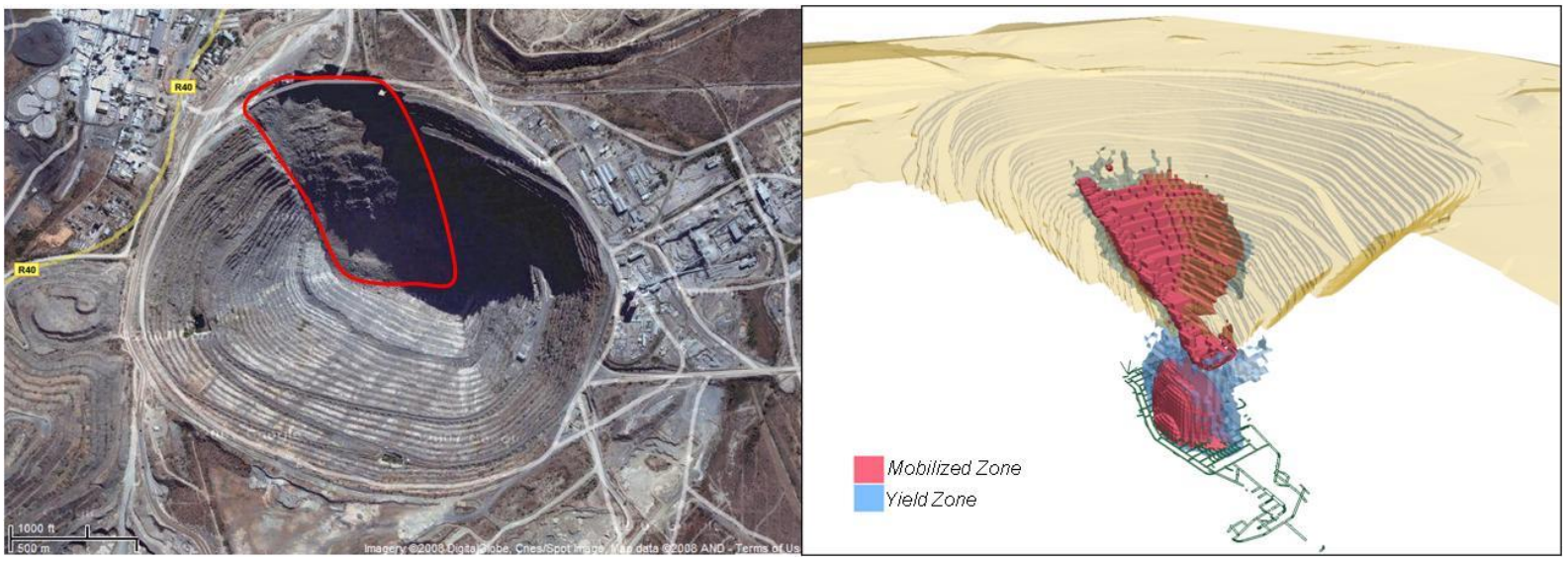

(a)

(b)

Figure 9 The Palabora pit slope failure mechanism reproduced by the SRM-UJRM approach for representing jointed rock masses

Evolution of the pit slope failure mechanism is illustrated in Figure 10. An increase in production draw from the western portion of the mining footprint is observed to cause a rapid vertical advance of the yield zone which intersects the base of the pit. Breakthrough of the cave volume is observed to mobilise the sub-vertical joints in the pit slope immediately above the yielded zone.
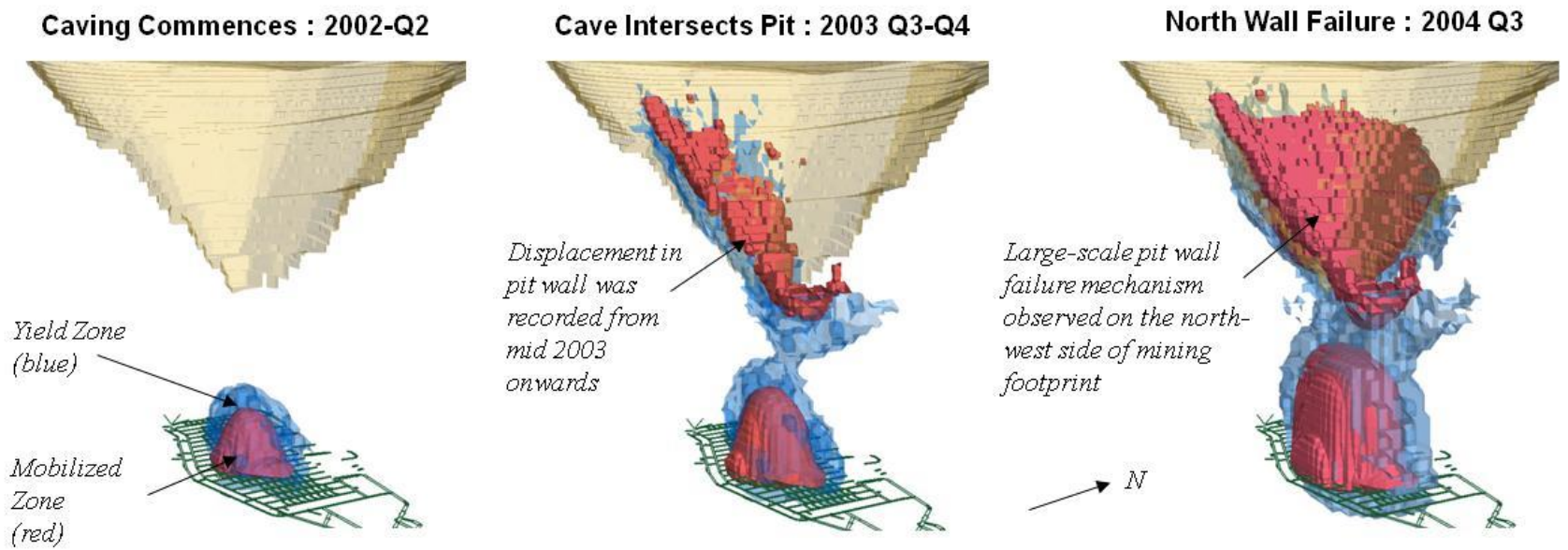
Figure 10 Development of the pit slope failure mechanism at the Palabora mine at various stages of
production

The location and magnitude of seismic events recorded during the early stages of production at the Palabora mine are illustrated in Figure 11(a). Based on this data, the location of the yield zone (or aseismic zone) has been inferred to extend approximately $55-83 \mathrm{~m}$ beyond the cave zone. As illustrated in Figure 11(b), the predicted yield zone extends approximately $50-80 \mathrm{~m}$ above the cave zone, providing a good correlation with the monitored seismicity. 

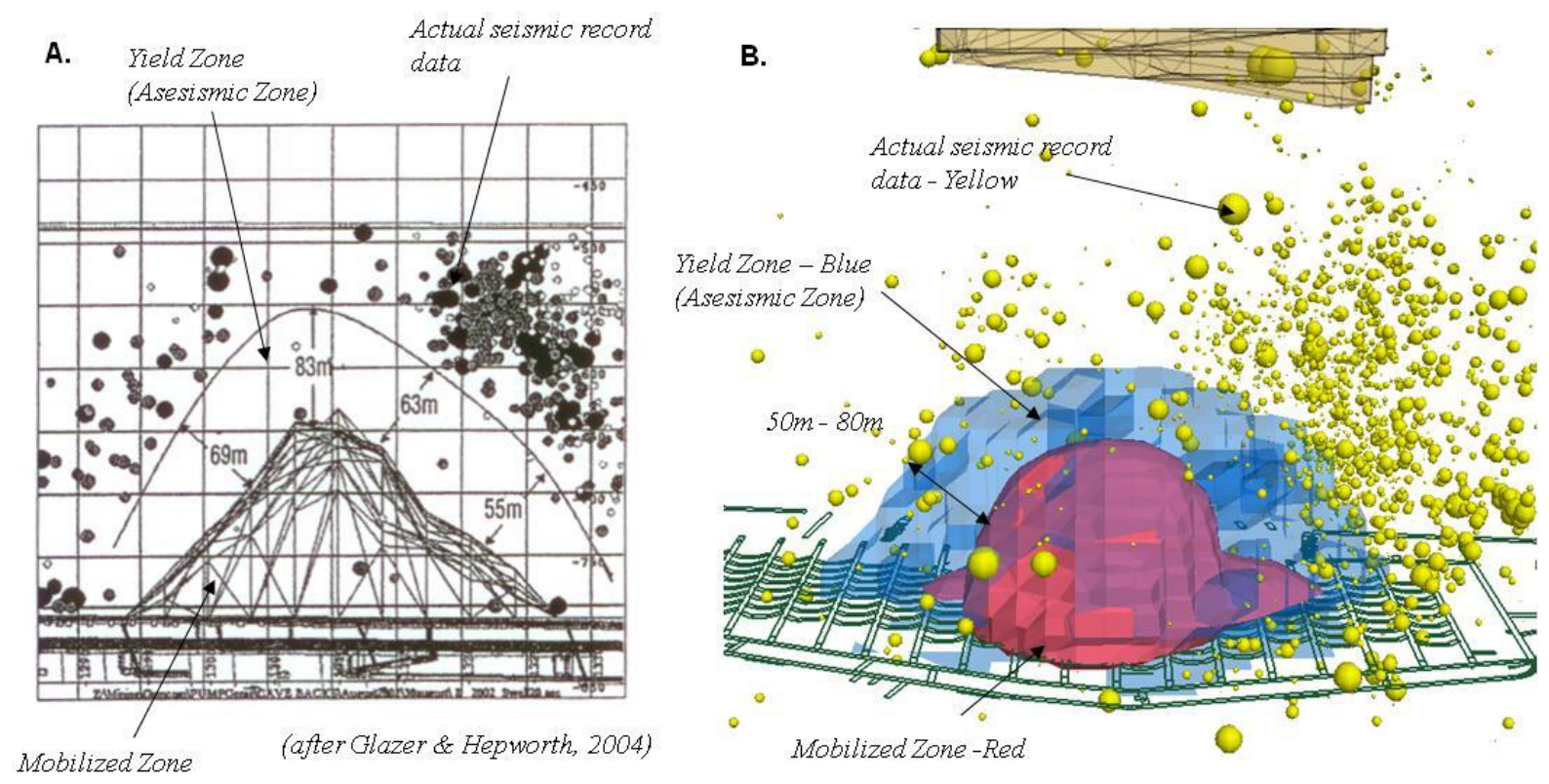

Figure 11 (a) Observed mobilised, yield and seismogenic zones at Palabora during production (after Glazer and Hepworth, 2004); (b) Numerical prediction of mobilised and yield zones presented with actual seismic record data during production at the Palabora mine

The seismogenic zone has been predicted at various stages of production in the numerical model using the methodology described by Diederichs (1999), and outlined in Section 3.1 of this paper. As illustrated in Figure 12, the seismogenic zone is seen to manifest immediately beneath the floor of the open pit in the early stages of mining. As mining progresses and the crown pillar fails, seismicity migrates to the lateral extents of the mining footprint, prior to progressing beneath the extraction level as production continues. This sequence is consistent with the seismic record collected on site and discussed by Glazer and Hepworth (2006).

Caving Commences : 2002-Q2

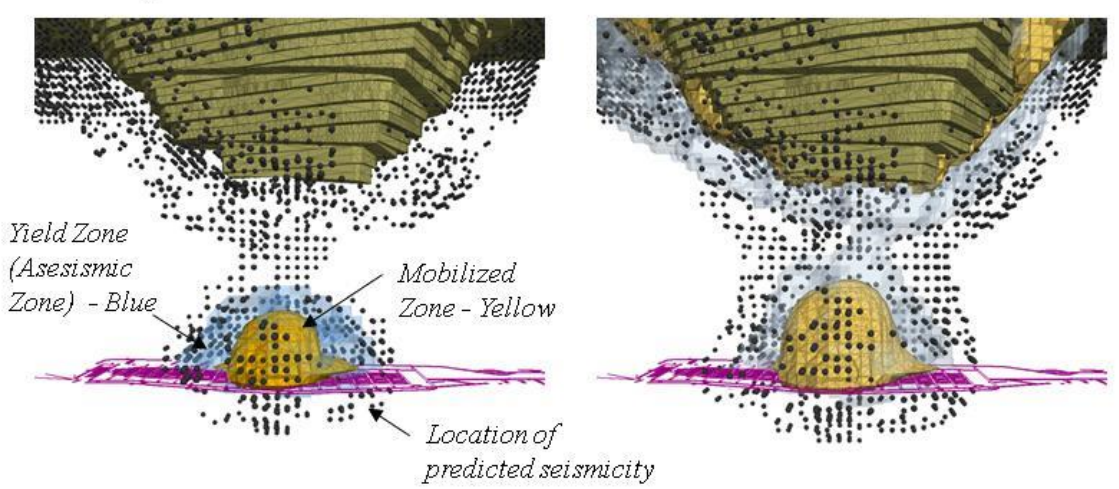

North Wall Failure : 2004 Q3

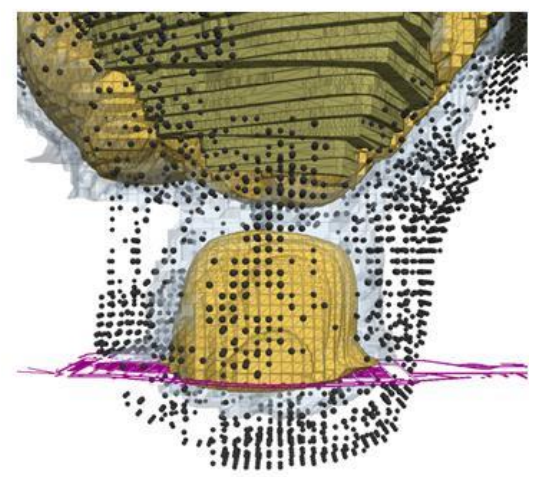

Figure 12 Migration of the predicted seismogenic zone during production at the Palabora mine

\section{Conclusions}

A technique has been developed using $F L A C 3 D$ to reproduce the rock mass strength anisotropy and scale effects derived from SRM testing. Application of this technique to cave-scale analysis shows that significant affects on the cave shape and rate of progression can be obtained by variations in the rock mass joint orientation and persistence. The SRM-UJRM approach has successfully been applied to re-create the slope failure mechanism at the Palabora mine in South Africa. Continued developments of this methodology continue through support of the MMT research project. 


\section{Acknowledgements}

The authors wish to acknowledge Rio Tinto, and other the members of the MMT project for sponsoring the development of the SRM-UJRM methodology. In addition, the authors would like to thank Juan ReyesMontes from Applied Seismology Consultants for his involvement in the development of SRM seismic validation techniques. Thanks also go to Northparkes and the Palabora mine for the approval to publish this work and for their continued interest and support of the SRM-UJRM technology.

\section{References}

Brummer, R.K., Li, H. and Moss, A. (2006) The transition from open pit to underground mining: An unusual slope failure at Palabora. The South African Institute of Mining and Metallurgy, International Symposium on Stability of Rock Slopes in Open Pit Mining and Civil Engineering, April, pp. 411-420.

Clark, I. (2006) Simulation of rock mass strength using ubiquitous joints, Numerical Modelling in Geomechanics 2006, Proceedings 4th International FLAC Symposium, May, R. Hart and P. Verona (editors), Paper No. 08-07, Minneapolis, Itasca.

Diederichs, M.S. (1999) Instability of Hard Rockmasses: The Role of Tensile Damage and Relaxation. PhD thesis, University of Waterloo.

Duplancic, P. and Brady, B.H. (1999) Characterization of caving mechanisms by analysis of seismicity and rock stress, Proceedings 9th International Congress on Rock Mechanics (Paris) Vol. 2, pp. 1049-1053. Balkema, Rotterdam.

Glazer, S. and Hepworth, N. (2006) Crown pillar failure mechanism - case study based on seismic data from Palabora Mine. Mining Technology, Vol. 115, No. 2, pp. 75-84.

Glazer, S. and Hepworth, N. (2004) Seismic monitoring of block cave crown pillar - Palabora Mining Company, RSA. Massmin, Santiago, Chile, 22-25 August, pp. 565-569.

Itasca Consulting Group, Inc. (2006) FLAC3D - Fast Lagrangian Analysis of Continua in 3 Dimensions, Ver. 3.1, User's Manual. Minneapolis, Itasca.

Itasca Consulting Group, Inc. (2007a) PFC3D - Particle Flow Code in 3 Dimensions, Ver. 4.0 pre-release. Minneapolis, Itasca.

Itasca Consulting Group, Inc. (2007b) 3DEC - Three Dimension Distinct Element Code, Ver. 4.1. Minneapolis, Itasca.

Laubscher, D.H. (2000) Block caving manual. Prepared for International Caving Study. JKMRC and Itasca Consulting Group, Brisbane.

Lorig, L. and Pierce, M. (2000) Methodology and Guidelines for Numerical Modelling of Undercut and Extraction Level Behaviour in Caving Mines. Itasca Consulting Group Inc, Report to International Caving Study.

Mas Ivars, D., Pierce, M., DeGagné, D. and Darcel, C. (2008) Anisotropy and scale dependency in jointed rock mass strength - A synthetic rock mass study. Proceedings First International FLAC / DEM Symposium on Numerical Modeling, R. Hart, C. Detournay and P. Cundall (editors), 25-27 August, Minneapolis, US. Minneapolis, Itasca (in press).

Pierce, M., Cundall, P., Potyondy, D. and Mas Ivars, D. (2007) A Synthetic Rock Mass Model for Jointed Rock. Rock Mechanics, Meeting Society's Challenges and Demands - E. Eberhardt, D. Stead and T. Morrison (editors), Taylor and Francis Group, London, pp. 341-349.

Sainsbury, B., Pierce, M. and Mas Ivars, D. (2008) Simulation of rock mass strength anisotropy and scale effects using a Ubiquitous Joint Rock Mass (UJRM) model. Proceedings First International FLAC/DEM Symposium on Numerical Modelling, 25-27 August, Minneapolis, US. Minneapolis, Itasca (in press). 
